\title{
Modeling Huntington's Disease: in vivo, in vitro, in silico
}

\author{
Nagehan Ersoy Tunalı \\ Haliç University, Department of Molecular Biology and Genetics, İstanbul \\ Turkey
}

\section{Introduction}

Since the discovery of the Huntington's Disease (HD) gene (Huntington's Disease Collaborative Research Group, 1993) various research groups have aimed to discover the subcellular and tissue distribution of its mRNA and protein. The human HD gene is expressed ubiquitously in all human tissues as two major messenger RNA (mRNA) transcripts, $13.6 \mathrm{~kb}$ and $10.3 \mathrm{~kb}$ in length, which differ in the size of their 3' UTRs due to differential polyadenylation (Trottier et al., 1995). HD mRNA is expressed in both neural and non-neural tissues with high levels of expression in brain and testis (Sharp et al. 1995; Strong et al. 1993). Northern blot and in situ hybridization analyses indicate that the two transcripts are expressed in many human tissues (heart, kidney, lungs, pancreas, muscles, liver, placenta) with higher expression of the longer transcript in the brain (Strong et al., 1993; Sharp et al., 1995). In the brain, highest levels were found in cerebral cortex and cerebellum, intermediate levels in the hippocampus and the lowest levels in the caudate nucleus and thalamus (Li et al., 1993). In addition to this, neuronal expression predominates over glial expression (Strong et al., 1993). No difference in the mRNA expression pattern between HD brains and controls was reported (Landwehrmeyer et al., 1995). The HD gene encodes a protein of 3144 amino acids with a molecular mass of $348 \mathrm{kDa}$, termed huntingtin (htt). The polyQ tract starts at residue 18 and is followed by a stretch of prolines. Similar to RNA studies, protein studies also indicate ubiquitous expression of htt in a variety of cells and tissues throughout the development and in the adult (Zeitlin et al., 1995) in both brain and peripheral tissue (Hoogeveen et al., 1993; Jou and Myers, 1995; Sharp et al., 1995). Normal huntingtin is widely distributed in the body, with the highest levels in the brain and testis. In HD patients, normal and mutant huntingtin have similar distribution and expression patterns (Sharp et al., 1995; Trottier et al., 1995).

The pathology of HD is restricted to the brain, medium spiny GABA-ergic striatal neurons are selectively lost (Graveland et al., 1985). The neuronal intranuclear inclusions (NII), which contain the N-terminal fragment $\mathrm{htt}$, are accepted as neuropathological markers of HD (Davies et al., 1997; DiFiglia et al., 1997; Juenemann et al., 2011). Since htt has no known homologies to any other protein, it is not easy to assign its exact function(s) and therefore to identify the mechanisms involved in disease process. The molecular mechanism underlying HD pathogenesis has been explained by toxic gain of function of the mutant htt (Housman, 1995; Jacobsen et al., 2011). However, recent findings point out loss of function of the normal protein as a contributor to the disease process (Dragatsis et al., 2000; Zuccato et al., 2001). 
The exact cellular and subcellular localization of htt should be regarded as a key to understand the tissue-specific death in HD and the underlying molecular mechanisms. In this regard, localization of both the endogenous and overexpressed htt has been investigated by several research groups in cell lines, animal models, and post-mortem patient tissues. However, there is still no certain agreement on the precise subcellular distribution of huntingtin. Although original observations indicated an exclusively cytoplasmic localization (DiFiglia et al., 1995; Gutekunst et al., 1995; Sharp et al., 1995), recently both normal and mutant htt have been reported in the nucleus (Bae et al., 2006; Havel et al., 2011; Kegel et al., 2002; Tanaka et al., 2006; Yan et al., 2011). Three putative NLS were identified, but later they were shown to be non-functional (Hackam et al., 1998; Xia et al., 2003); and it is still not very clear how htt is transported into the nucleus. A detailed analysis of the subcellular distribution of htt may provide suggestions for its possible roles.

The current debate about the precise localization of htt emerges mostly from the diversity of experimental setups and the methods used. In post-mortem studies, handling of the tissue and the method of fixation have important effects on the following staining pattern. In analyzing endogenous protein expression in cell lines by immunocytochemistry methods, cell type (neuronal/non-neuronal), fixation methods, and the specificity of the antibodies are the major determinants of the subsequent detection of localization. Much less controllable variables like culture conditions may also have important effects on cell cycle and growth. Any interruptions or changes in cell cycle programme may change the localization of the proteins (Martin-Aparico et al., 2002). Various antibodies directed to N- or C-terminal regions of htt have been used to detect htt in various cell lines, but the results are contraversial (DiFiglia et al., 1995; De Rooij et al., 1996, Wilkinson et al., 1999). In overexpression systems, localization of normal and mutant htt can be studied more extensively, since htt constructs of various sizes and polyQ lengths can be created. In this case, the associated tag may have substantial effects on the subcellular localization. Large tags may prevent nuclear localization of the proteins. In overexpression systems, size of the huntingtin construct and the associated repeat length proved to have major impacts on subcellular localization, and these two criteria should always be considered together, since the repeat length alone cannot determine the localization. Overexpressed htt can be visualized in fixed or live cells. To overcome the drawbacks of working with fixed cells, proteins can be fluorescently tagged and the transfected cells can be analyzed in their natural environments. In recent protein expression and localization studies, live cell analysis using fluorescent recombinant vectors have been the preferred method of choice. Use of laser scanning confocal microscopy (LSCM) adds more power, since it enables simultaneous multi-channel imaging of two or more fluorescent proteins, and cellular transfections can be analyzed in space and time.

Considering the above mentioned factors affecting htt localization, this study was constructed to establish the endogenous and overexpressed, wild type and mutant, full length (FL) and truncated htt localizations in cell lines and in HD mouse models. These various constructs, run under the same experimental conditions are expected to provide a full delineation of htt localization. In this regard, the expression pattern of endogenous and overexpressed htt was investigated in neuronal and non-neuronal cell lines (HEK 293, N2A, PC12, IMR32) and embryonic striatal neurons of R6/1 and HdhQ150 mice expressing truncated and FL htt, respectively. In addition to localization studies, 3D htt structure was analyzed using fold recognition model and in silico polyQ expansion mutations were created 
in the htt protein using VMD programme which will help to decipher the effects of the mutation on protein structure and function.

\section{Endogenous htt expression}

\subsection{Maintenance of cell lines}

Endogenous htt expression was investigated in HEK 293, N2A, PC12 and IMR32 cell lines using immunocytochemistry methods. All cell lines were purchased from ECACC and maintained in their respective growth medium at a density of $2-5 \times 100.000$ cells $/ \mathrm{ml}$, in a humid $37^{\circ} \mathrm{C}$ incubator supplied with $5 \% \mathrm{CO}_{2}$. HEK 293 and N2A cells were grown in culture flasks in MEM supplemented with penicillin/streptomycin (100 units $\left.\mathrm{ml}^{-1} / 100 \mu \mathrm{g} \mathrm{ml}^{-1}\right)$, glutamine $(2 \mathrm{mM}), 1 \mathrm{X}$ non-essential amino acids (NEAA) and 10\%FBS. PC12 cells were grown in complete RPMI 1640 medium, consisting of RPMI 1640, penicillin/streptomycin (100 units $\left.\mathrm{ml}^{-1} / 100 \mu \mathrm{g} \mathrm{ml}^{-1}\right)$, glutamine $(2 \mathrm{mM})$ and $10 \% \mathrm{FBS}$. They were differentiated with NGF- $\beta$ (100 ng/ml) when needed. IMR32 cells were grown adherent to culture flasks in complete RPMI 1640 containing penicillin/streptomycin (100 units ml-1/ $\left.100 \mu \mathrm{g} \mathrm{ml}^{-1}\right)$, glutamine ( $2 \mathrm{mM}$ ) and 5\% FBS. HEK 293, N2A and IMR32 cells were adherent and were passaged every four days. PC12 cells grow in suspension, but can be made adherent by coating the flasks with poly-D-lysine.

\subsection{Immunostaining methods}

One of the important steps in protein localization by immunostaining methods is the fixation of cell preparations. The cells should be appropriately fixed and permeabilized prior to staining. There are organic solvents and cross-linking fixatives available, both having advantages and disadvantages. Use of organic solvents may be regarded as much less toxic and time-saving since permeabilization is not required, rehydration in Phosphate Buffered Saline (PBS) prior to staining procedure is enough. However, cross-linking fixatives may fix the cells better on the slides, but cells will need permeabilization prior to staining. In this study both the organic solvents (methanol, acetone) and a cross-linking fixative (paraformaldehyde) were utilized in order to decipher their effects on staining patterns (Table 1). It was shown that fixation with organic solvents can mask epitope binding sites (Figure 1a), and paraformaldehyde fixations followed by Triton-X-100 permeabilization reveal better staining patterns (Fig. 1.b). In the framework of this study, $4 \%$ paraformaldehyde fixation at room temperature (RT) followed by $0.1 \%$ Triton-X-100 permeabilization was used to determine endogenous htt localizations.

\begin{tabular}{|l|l|}
\hline Fixation & Permeabilization \\
\hline $4 \%$ paraformaldehyde, 15 mins at RT & $0.1 \%$ Triton-X-100, 20 mins at RT \\
\hline $4 \%$ paraformaldehyde, 15 mins at RT & $0.5 \%$ Triton-X-100, 20 mins at RT \\
\hline Methanol at $-20^{\circ} \mathrm{C}, 5$ mins; air dry \& rehydrate in 1XPBS & - \\
\hline $\begin{array}{l}\text { Acetone at }-20{ }^{\circ} \mathrm{C}, 10 \mathrm{mins} \text {, air dry \& rehydrate in 1X PBS } \\
\text { Methanol/ Acetone mix at }-20^{\circ} \mathrm{C}, 10 \text { mins, air dry \& } \\
\text { rehydrate in 1X PBS }\end{array}$ & - \\
\hline
\end{tabular}

Table 1. Cell fixation methods. 


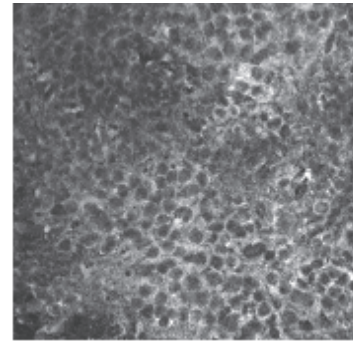

a

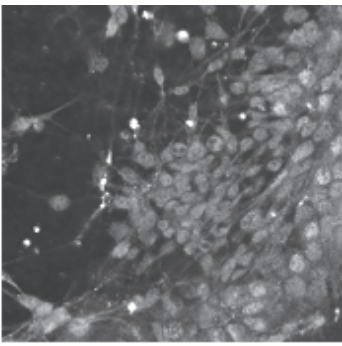

b

Fig. 1. R6/1 embryonic striatal cells, immunostained with the N675 antibody after (a) 100\% $\mathrm{MeOH}$ and (b) $4 \%$ paraformaldehyde fixations.

Following fixation, cells were blocked in $10 \%$ serum of the host of the secondary antibody for $1 \mathrm{hr}$, and then incubated with the primary antibody diluted in 1\% serum, for an hour at $37{ }^{\circ} \mathrm{C}$. Following washes in $1 \mathrm{X}$ PBS with three changes in $1 \mathrm{hr}$, secondary antibody in $1 \%$ serum was applied to the cells, and incubated for $1 \mathrm{hr}$ at $37{ }^{\circ} \mathrm{C}$. Finally, cells were washed in 1X PBS and mounted with fluorsave reagent. Subcellular htt localization was determined using antibodies directed to different regions of the protein (Table 2)

\begin{tabular}{|l|l|l|}
\hline Antibody & Description & Detection \\
\hline N675 & Rabbit polyclonal, gift from Dr. Lesley Jones (UK) & against amino acids 1-17 \\
\hline HDA & Mouse monoclonal, gift from Dr. Glenn Morris (UK) & against amino acids 997-1276 \\
\hline HDC & Mouse monoclonal, gift from Dr. Glenn Morris (UK) & against amino acids 2703-2911 \\
\hline
\end{tabular}

Table 2. Primary antibodies used to localize endogenous htt.

\subsection{Endogenous htt localization}

N675 antibody should detect the first 17 amino acids of htt, just prior to the polyQ tract. Therefore, it should catch up the FL htt protein and any N-terminal cleavage products. HEK293 cells showed strong granular cytoplasmic staining with N675, and nuclear signal was restricted to a few small puncta (Fig.2.a). On the other hand, N2A cells exhibited strong diffuse nuclear staining (Fig.2.b,c). PC12 cells, when treated with NGF, showed one to two nuclear puncta, otherwise they showed a cytoplasmic staining pattern (Fig.2.d,e).

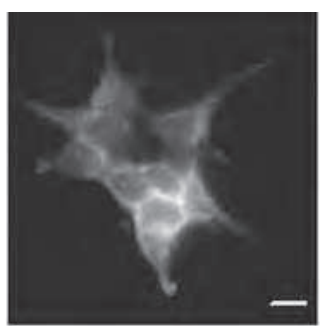

a

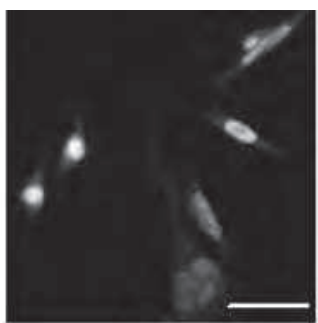

b

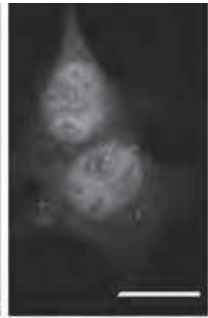

C

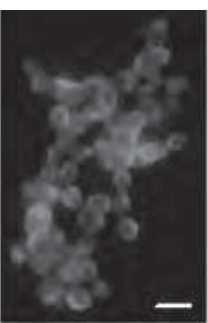

d

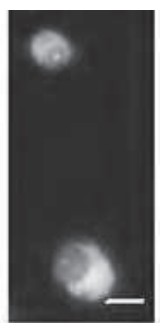

e

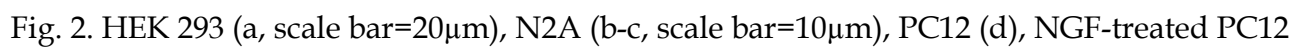
(e, scale bar $=20 \mu \mathrm{m}$ ) cells immunostained with N675. 
The localization and expression pattern of endogenous htt was further analyzed using another N-terminal antibody, HDA. This mouse monoclonal antibody was raised against the htt amino acids 997-1276, therefore it should detect the FL htt protein and any Nterminal cleavage products. HDA antibody caught very distinctive htt inclusions in HEK293 cells (Fig.3.a). However, N2A (Fig.3.b) and PC12 cells (Fig.3.c) showed homogenous nuclear localization, with a few puncta in higher expressing N2A cells. IMR32 cells generally demonstrated a nuclear expression with perinuclear inclusions in some cells (Fig.3.d, Fig4).

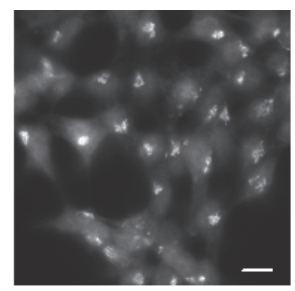

a

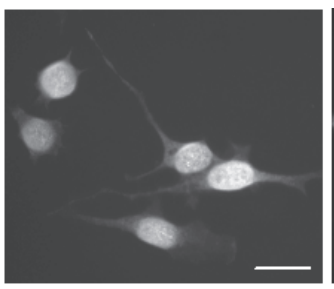

$\mathrm{b}$

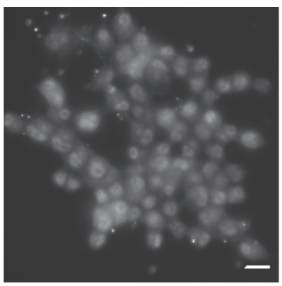

C

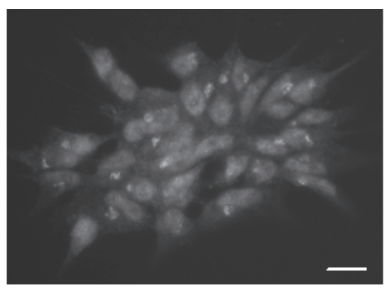

d

Fig. 3. HEK 293 (a), N2A (b), NGF-treated PC12 (c), IMR32 (d) cells immunostained with HDA (scale bars $=20 \mu \mathrm{m}$ for $(\mathrm{a})$ and (c), $10 \mu \mathrm{m}$ for $(\mathrm{b})$ and $(\mathrm{d})$ ).

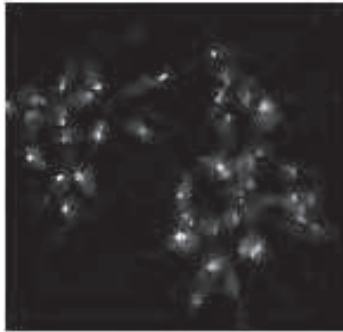

a

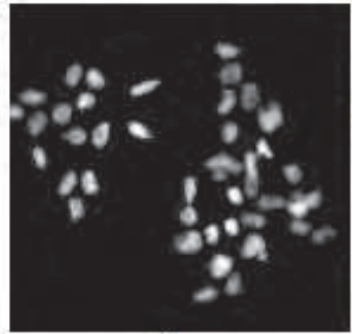

b

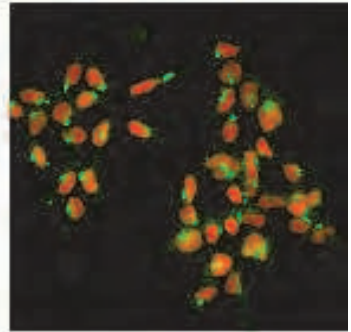

C

Fig. 4. Htt localization in IMR32 cells with HDA (a), nuclear staining with PI (b) and merged image (c).

The localization of endogenous htt also assessed by using a C-terminal antibody, HDC. This mouse monoclonal antibody was raised against amino acids 2703-2911, therefore expected to catch up FL htt and any C-terminal cleavage products. All cell types studied showed exclusively cytoplasmic localization and diffuse expression with the HDC antibody. HEK293 cells showed diffuse cytoplasmic localization, and occasionally, one inclusion per cell was noticed (Fig.5.a). In N2A cells, in addition to diffuse cytoplasmic staining, there was higher expression in the dendrites and nerve terminals (Fig.5.b.), cytoplasmic aggregates were noticed only in a few cells. In PC12 cells, htt expression was in the form of cytoplasmic punctates (Fig.5.c), and when treated with NGF, localization was extended to dendrites (Fig.5.d.). IMR32 cells showed diffuse cytoplasmic expression (Fig.5.e.). 


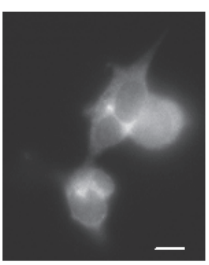

a

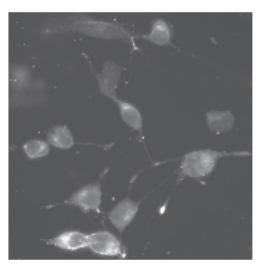

$\mathrm{b}$

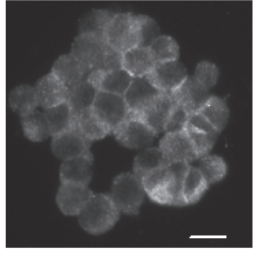

C

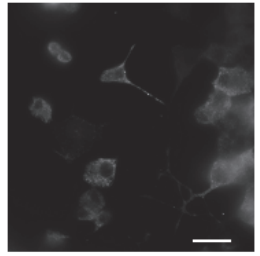

d

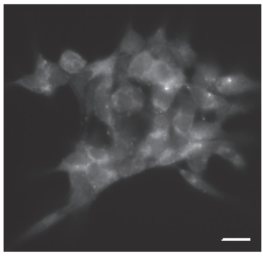

e

Fig. 5. HEK 293 (a), N2A (b), PC12 (c), NGF-treated PC12 (d), IMR32 cells (e) immunostained with HDC (scale bars $=20 \mu \mathrm{m})$.

\section{Htt overexpression in HD cell models}

\subsection{Cloning full length huntingtin into PEYFP-C1}

Green fluorescent protein (GFP), extracted from the jellyfish Aequorea victoria, is a widely used fluorescent reporter molecule. GFP and its variants can be expressed as fusion constructs with other proteins to monitor dynamic cellular processes. Since it does not require any additional substrates to emit light, it is ideal for in vivo, in situ, and real time protein expression and localization studies (Chalfie\& Kain, 1998). In this study pEYFP-C1 and pEYFP-N1 vectors were used for cloning and expression studies of htt. Full length $(\mathrm{FL}) \mathrm{htt}(10 \mathrm{~kb})$ with normal and expanded CAG repeats were cloned into yellow fluorescent vector, pEYFP-C1. For this purpose, FL htt25Q and FL htt82Q sequences were first released from the pRcCMV vector (Cooper et al., 1998), which were generously provided by Dr. Christopher Ross (Johns Hopkins School of Medicine, USA), with BstZI and NotI restriction enzymes. FL htt was cut just before the ATG start codon and just after the polyA tail of htt, respectively. FL htt sequences were inserted into EcoRI-digested pEYFP-C1 vector (Fig.6.a). Ultracompetent Epicurian coli XL2 Blue cells were transformed with the ligation products and grown on kanamycin-containing agar plates at $37{ }^{\circ} \mathrm{C} \mathrm{o} / \mathrm{n}$. Bacterial colonies, which have taken up the ligation constructs, were selected first by filter hybridization and then with sequencing. After verification of the sequence frames, successful clones were maxi-preped.

\subsection{Cloning truncated huntingtin into pEYFP-N1}

The constructs containing only the exon1 of the htt gene with 23 and 65 CAG repeats in the pcDNA6c-myc/His vector were kind gifts from Dr.Mark Lesort (The University of Alabama at Birmingham. Truncated htt sequences were released from this vector with BamHI and XhoI restriction enzymes, and ligated into NheI- and XhoI-digested pEYFP-N1 vector (Fig.6.b). Ultracompetent Epicurian coli XL2 Blue cells were transformed with the ligations and were grown on kanamycin-containing agar plates at $37 \circ \mathrm{Co} / \mathrm{n}$. The transformed bacterial colonies were subjected to sequencing to confirm vector-insert junction sequences and the CAG repeat size. 


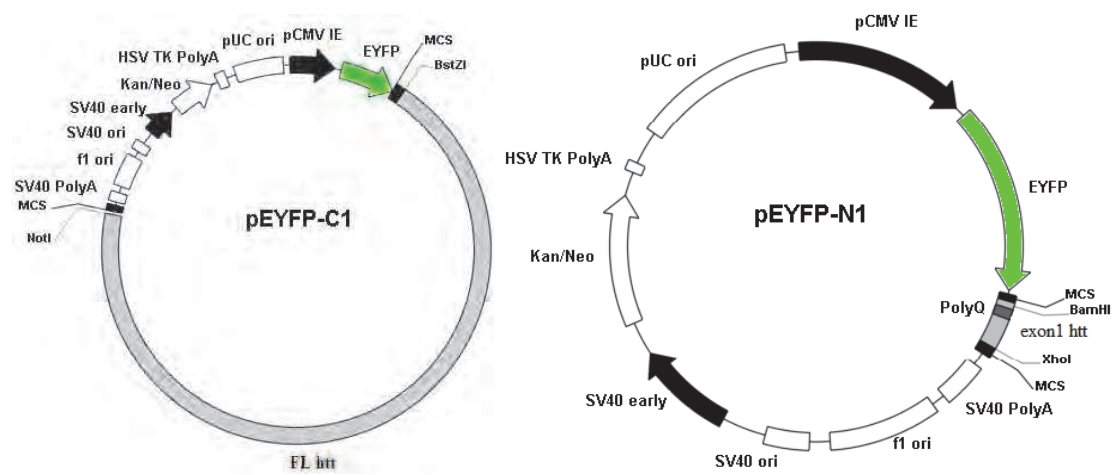

Fig. 6. Vector diagrams for FLhtt- pEYFPC1 (a) and Ex1htt- pEYFPN1 (b).

\subsection{Transient transfection and microscopy}

Transient transfections of cell lines with plasmid DNAs were carried out in 6-well plates, using Fugene6 (Roche) according to the instructions provided. Following transfection, localizations were visualized by both conventional fluorescence microscopy and LSCM. Living colors fluorescent proteins can be visualized with fluorescence microscopes, and can be independently distinguished using filter sets specific for each color. Images are acquired with a cooled charge-coupled device (CCD) camera. Live cells expressing fluorescent fusion proteins, or fixed cells prepared by immunocytochemistry were visualised under the 40X objective of the Zeiss Axiovert-S100 TV fluorescence microscope equipped with appropriate filters. The collected images were analyzed using Kinetic Imaging software. In confocal microscopy, images are produced by scanning the cells. When the light source is a laser beam, it is called LSCM. Scanning the object in $\mathrm{x}_{-}^{-}, \mathrm{y}_{-}^{-}$, and $\mathrm{z}$-directions along the optical axis allows visualization of the object from all sides. In conventional fluorescence microscopy, co-localization of different proteins is performed using different filter sets sequentially. However, in LSCM, each detector is equipped with its filter sets to enable simultaneous multi-channel imaging of two or more fluorescent proteins. In this study, the BioRad 1024MP laser scanning microscope system was used to analyse live and immunostained fixed cells. Zeiss Axiovert-S100 TV microscope was attached to the 1024 scan head. Live cell EYFP fluorescence was detected with a krypton-argon ion laser at $488 \mathrm{~nm}$. Two dimensional $(\mathrm{x}, \mathrm{y})$ high resolution images $(512 \times 512)$ were collected with 40X, 1.3 NA oil immersion lens and filtered eight times with Kalman filter. For live cell analysis, three dimensional images were also captured for the purpose of spatial localization.

\subsection{FL htt overexpression}

HEK293, N2A and PC12 cells were transiently transfected with FL normal and mutant htt, in the form of YFP fusion constructs. Mutant htt originally contained 82 CAG repeats; however, the repeat size was contracted to 60 and expanded to 90 CAGs during bacterial transformation. Transfected cells were analyzed live, since derivatives of GFP expression vectors allow direct analysis of the cells, without the need for fixation or staining. As a first step, localization and expression of the pEYFPC1 vector itself, which encodes a $27 \mathrm{kDa}$ fluorescent protein, was analyzed. Expression was mostly localized to the nucleus in all cell 
types examined and showed a diffuse expression pattern, excluding nucleoli. In addition to that, very weak expression in the cytoplasm and dendrites were noticed (Fig.7.).
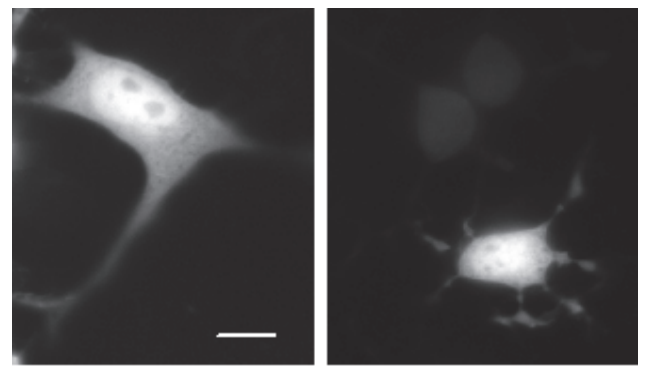

Fig. 7. pEYPC1 expression and localization in N2A cells (scale bar=10 $\mu \mathrm{m}$ ).

Full length wild type htt (FL htt25Q-YFP) expression was studied on a time scale in HEK293 cells. Transfected HEK 293 cells started to express htt-YFP fusion proteins four hours after transfection. As far as it was expressed, htt showed a diffuse cytoplasmic expression pattern. Transient transfections of wild type and mutant htt were analyzed for $72 \mathrm{hr}$ in HEK293, N2A, and PC12 cells, however, the overexpressed proteins did not change their cellular localization. Wild type htt-YFP expression was studied also with laser scanning confocal microscopy, which revealed a homogenous cytoplasmic expression in HEK293 cells (Fig.8.a). Cells expressing FL mutant htt-YFP also demonstrated diffuse cytoplasmic expression (Fig.8.b,c). However, more cells presented inclusions and apoptotic features, like big vacuoles, membrane blebbing and cellular dissociation (Fig.9.).

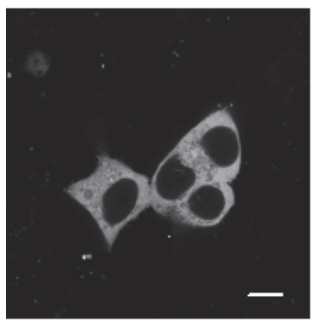

a

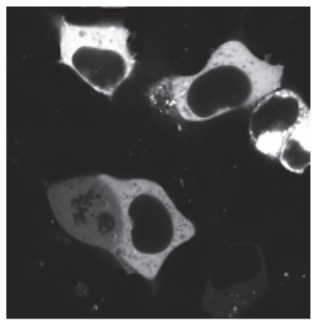

$\mathrm{b}$

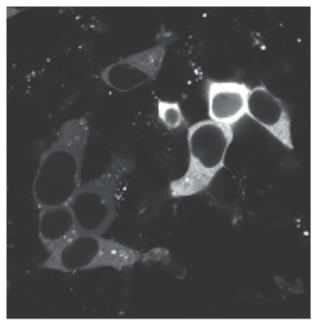

$\mathrm{C}$

Fig. 8. LSCM images of FL htt25Q-YFP (a), FL htt60Q-YFP 8b), FL htt90Q-YFP (c) expression in HEK293 cells (scale bar $=20 \mu \mathrm{m}$ ).

Huntingtin expression was also studied in live N2A cells, transfected with htt25Q-YFP (Fig.10.a), htt60Q-YFP (Fig.10.b), and htt90Q-YFP (Fig.10.c) constructs. All plasmids exhibited a diffuse cytoplasmic expression pattern. In addition, htt was expressed in dendrites at high levels. Cells expressing the wild type htt were healthy; however those expressing mutant htt presented apoptotic features, like big vacuoles and membrane blebbing.

Live PC12 cells transfected with FL htt25Q-YFP showed diffuse cytoplasmic expression, and all were healthy (Fig.11.a). In cells treated with NGF, expression was extended to the dendrites; PC12 cells expressing mutant htt presented small cytoplasmic inclusions and failed to grow neurites when treated with NGF (Fig.11.b,c). 


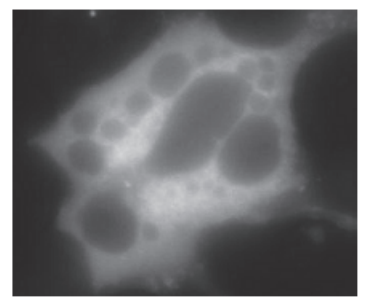

a

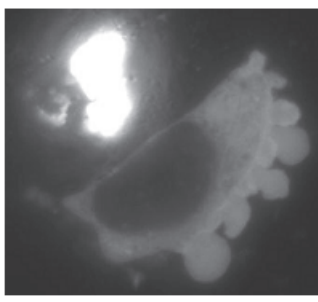

b

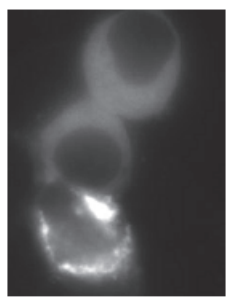

C

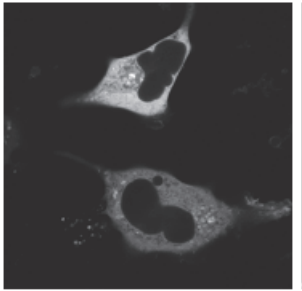

d

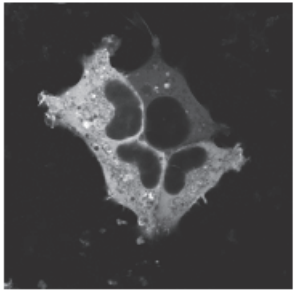

e

Fig. 9. FL htt60Q-YFP (a-c) and FL htt90Q-YFP (d,e) expressions in HEK cells as revealed by conventional fluorescence microscopy and LSCM, respectively.

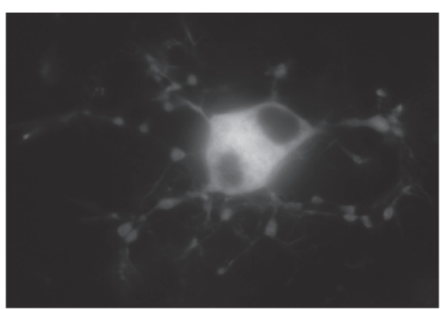

a

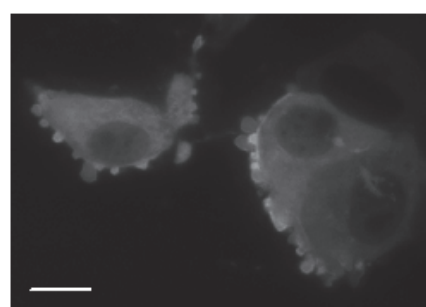

b

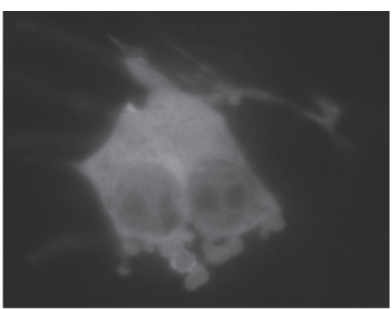

$\mathrm{C}$

Fig. 10. a) FL htt25Q-YFP, b) FL htt60Q-YFP and c) FL htt90Q-YFP expressions in N2A cells (scale bar $=10 \mu \mathrm{m})$.

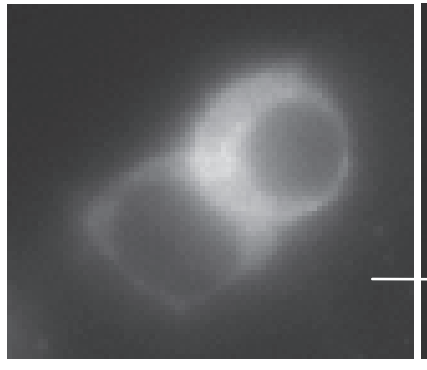

a

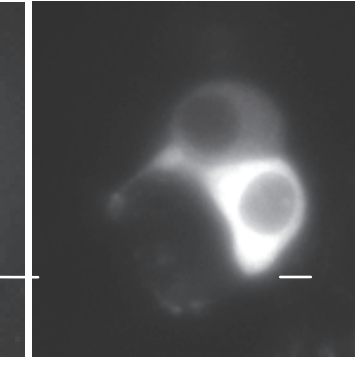

b

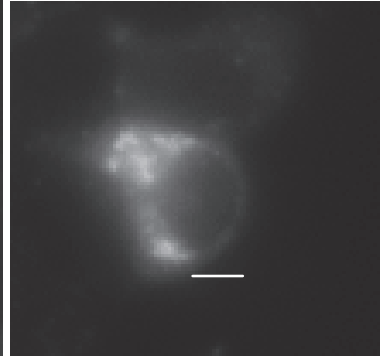

C

Fig. 11. a) FL htt25Q-YFP, b) FL htt60Q-YFP and c) FL htt90Q-YFP expressions in PC12 cells (scale bars $=20 \mu \mathrm{m}$ ). 
In order to eliminate the possible effects of the $27 \mathrm{kDa}$ fluorescent YFP tag on the localization of FL htt, HEK 293 (Fig.12.a), N2A (Fig.12.b), and PC12 cells (Fig.12.c) were transfected with untagged FL htt, and expression was detected with the N675 antibody. All transfected cells demonstrated diffuse cytoplasmic localization of both the wild type and mutant FL htt, as observed with FL htt-YFP constructs.

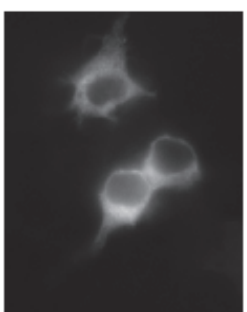

a

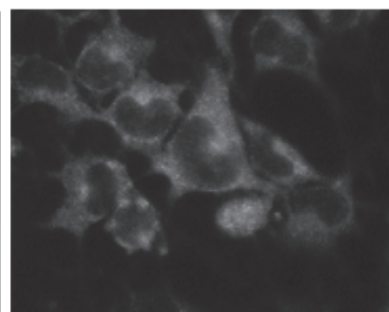

b

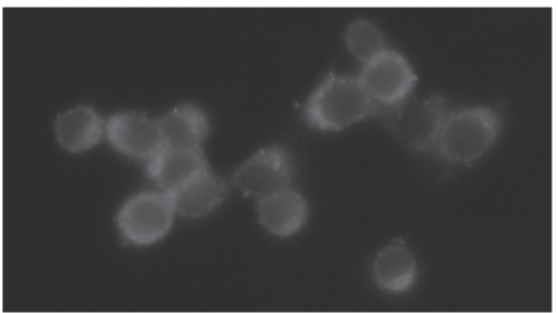

$\mathrm{C}$

Fig. 12. a) HEK293, b) N2A, c) PC12 cells transfected with untagged FL htt.

The viability of the cells transiently transfected with the wild type and mutant htt constructs were studied by Trypan Blue Exclusion and MTT Assays. The experiments were performed in triplicates and repeated three separate times. The viability of the transfected cells are shown in Table 3. The significance of the toxicity caused by htt overexpression was calculated with the two-sample t-test. According to the results, FL htt90Q-YFP ( $p=0.039)$, but neither FL htt 25Q-YFP nor FL htt60Q-YFP caused significant cell death after $24 \mathrm{hr}$ expression (at $95 \% \mathrm{CI}, \mathrm{p}=0.635$ and $\mathrm{p}=0.255$, respectively).

\begin{tabular}{|c|c|}
\hline Construct & Viability (\%) \\
\hline Untransfected & 88.0 \\
\hline pEYFP & 85.9 \\
\hline FL htt25Q-YFP & 74.8 \\
\hline FL htt60Q-YFP & 65.8 \\
\hline FL htt90Q-YFP & 62.4 \\
\hline
\end{tabular}

Table 3. Viability of the cells transfected with htt constructs.

The metabolic activity of the cells was investigated with the colorimetric MTT assay. The significance of toxicity created by the wt and mutant htt constructs were calculated with the two sample t-test). The data has shown that mutant htt $(\mathrm{p}=0.008)$, but not wt htt $(\mathrm{p}=0.22)$, created significant toxicity in the cells in $24 \mathrm{hr}$.

\subsection{Truncated htt overexpression in cell lines}

In order to gain insight into the localization of truncated htt, HEK 293 and N2A cells were transfected with the truncated wild type and mutant htt, containing only the Exon 1 in pEYFP-N1 expression vector. Wild type truncated htt23Q showed more nuclear but also cytoplasmic diffuse expression pattern. In the nuclei, one to four htt inclusions were observed (Fig.13.a,b). Truncated htt65Q exhibited the same pattern; however the inclusions were of bigger size (Fig.13.c). The number and size of the inclusions were increased after 72hr transfection (Fig.13.b,d). 


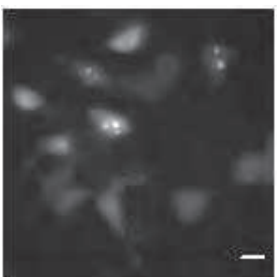

a

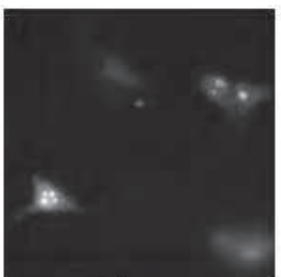

b

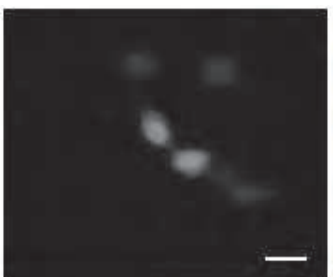

C

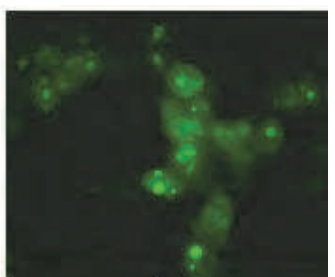

d

Fig. 13. Truncated htt23Q-YFP expression after $24 \mathrm{hr}$ (a) and $72 \mathrm{hr}$ (b) transfection in HEK293 cells; truncated htt65Q-YFP expression after $24 \mathrm{hr}(\mathrm{c})$ and $72 \mathrm{hr}(\mathrm{d})$ transfection in N2A cells (scale bars $=15 \mu \mathrm{m}$ ).

\section{Htt expression in HD mouse models}

The R6/1 and R6/2 mice were the first transgenic mouse models established to study HD. They both express only the exon 1 part of the human HD gene with 115 and 150 CAG repeats, respectively. The transgene is driven by the human huntingtin promoter. The transgene expression levels were identified as $31 \%$ and $75 \%$ of the endogenous huntingtin levels in the R6/1 and R6/2 mice, respectively (Mangiarini et al., 1996).

Endogenous and mutant htt expressions were analyzed in embryonic striatal neurons of two HD mouse models, R6/1 and HdhQ150. After breeding, pregnant female mice at E15 were sacrificed, embryos were removed and primary striatal cell cultures were prepared from E15 embryonic brains. The exact gestational stage of the embryos were determined by measuring the crown length. Embryos at E15 reach a crown length of 11-13 mm.

\subsection{Huntingtin expression in R6/1 mouse model}

Prior to analyze the htt expression pattern, primary striatal cells were stained for a widely expressed protein, $\beta$-tubulin III as a control for the protein expression level. Both wild type and R6/1 mutant embryonic striatal cells showed the same cytoplasmic localization and expression pattern (data not presented).

The N675 antibody showed a nuclear localization in both wild type (Fig.14.a) and mutant cells (Fig.14.b). The pattern of expression was occasionally punctate, but usually diffuse and homogenous, excluding nucleoli. Nuclear localization of htt was also demonstrated as costained with cytoplasmic $\beta$-tubulin III (Fig.15.).

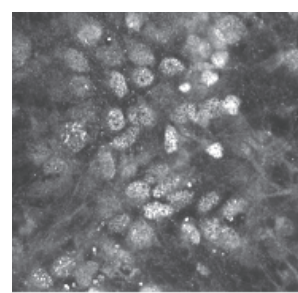

a

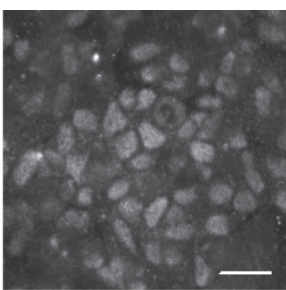

b

Fig. 14. LSCM images of N675-stained wt (a) and R6/1 (b) embryonic striatal cells (scale

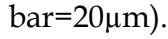




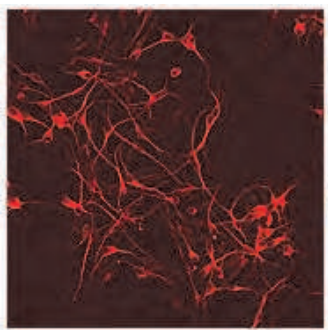

a

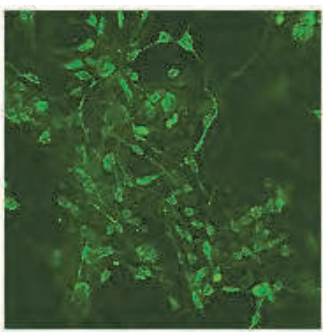

b

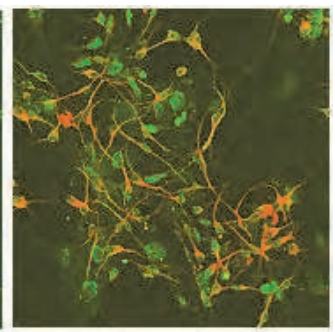

C

Fig. 15. Htt and $\beta$-tubulin III staining of embryonic striatal cells. a) $\beta$-tubulin III, b) htt, c) merged images.

Localization of htt was also assessed by the C-terminal antibody, HDC. This antibody revealed an exclusively cytoplasmic staining pattern of htt in both wild type (Fig.16.a) and R6/1 (Fig.16.b) primary striatal cells.

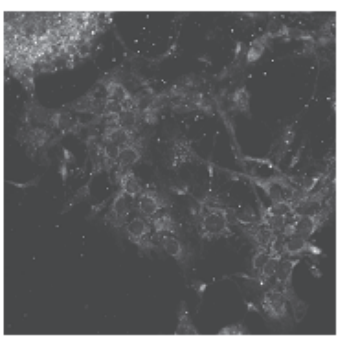

a

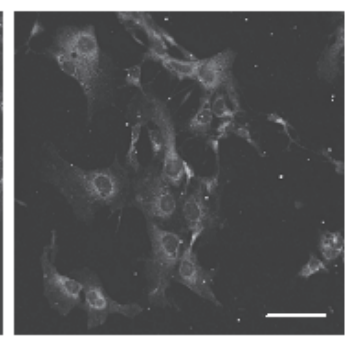

$\mathrm{b}$

Fig. 16. LSCM images of HDC-stained wt (a) and R6/1 (b) primary striatal cells (scale bar $=20 \mu \mathrm{m})$.

\subsection{Huntingtin expression in HdhQ150 mouse model}

HdhQ150 knock-in mice carry FL mutant htt with 150 glutamine residues, therefore represent a perfect replica of the mutant human HD gene (Lin et al., 2001). Heterozygous male HdhQ150 mice were bred with heterozygous female HdhQ150 mice, and primary striatal cell cultures were prepared from E15 embryonic brains. Prior to analyze the htt expression pattern, striatal cells were stained with $\beta$-tubulin III as a control. Both wild type and mutant primary striatal cells showed the same cytoplasmic localization, and the expression levels were not different (data not presented here). Striatal neurons were identified by immunostaining the cells with an antibody against dopamine- and cyclic AMP-regulated phosphoprotein, DARPP-32. The cultured cells were all DARPP-32 positive in their nuclei after seven days (data not presented here).

Huntingtin localization and expression pattern were analyzed in wild type, heterozygous and homozygous embryos using antibodies directed to N- and C- terminal htt protein. With N675, primary striatal cells of both wild type (Fig.17.a) and mutant embryos (Fig.17.b,c) demonstrated either punctate or diffuse expression in the nuclei, excluding nucleoli. Nuclear localization (Fig.17.d) was verified by the nuclear counterstain, Draq5 (Fig.17.e). 


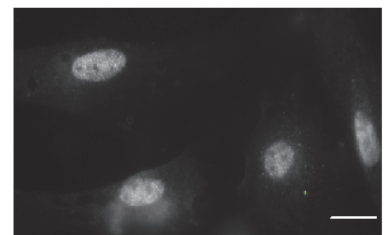

a

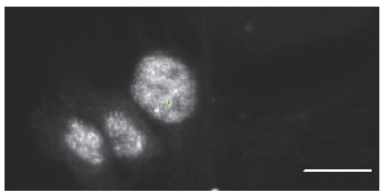

d

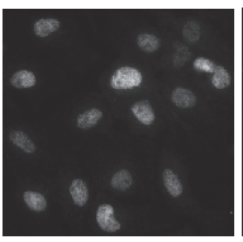

b

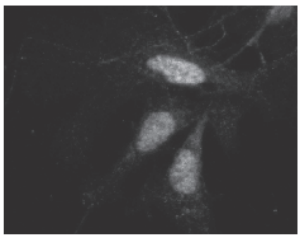

C

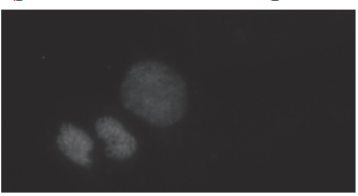

e

Fig. 17. N675 staining of HdhQ150 primary striatal cells (scale bars=10 $\mu \mathrm{m}$ ).

Localization of $\mathrm{N}$-terminal htt was further assessed using another $\mathrm{N}$-terminal antibody, HDA. This antibody detected htt in the nucleus, either diffuse or granular, in wild type (Fig.18.a), heterozygous (Fig.18.b) and homozygous mutant embryonic striatal cells (Fig.18.c).

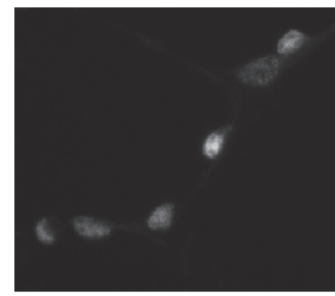

a

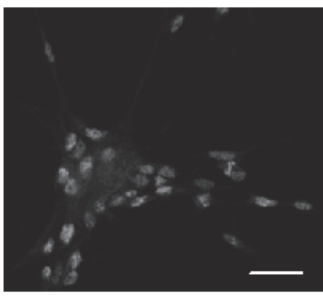

b

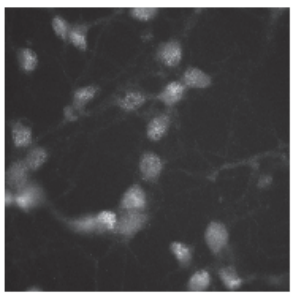

C

Fig. 18. HDA staining of HdhQ150 primary striatal cells (scale bar=20 $\mu \mathrm{m}$ ).

The antibody specific to the C-terminus of htt, HDC, revealed an exclusively cytoplasmic and diffuse staining pattern in both wild type (Fig.19.a) and heterozygous (Fig.19.b) and homozygous mutant (Fig.19.c) embryonic striatal cells.
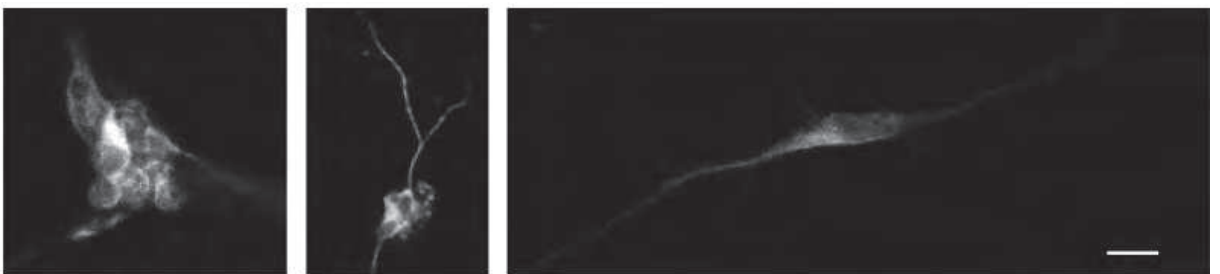

Fig. 19. HDC staining of HdhQ150 primary striatal cells (scale bar=20 $\mu \mathrm{m}$ ).

\section{Western blotting and htt expression}

Htt protein expressions were verified with SDS-PAGE and Western blotting. Protein samples extracted from transfected cell lines, quantified by Bradford Assay and subjected to SDS-PAGE electrophoresis. SDS-PAGE gels were blotted onto membranes for subsequent detection with 
the antibodies. Overexpressed htt was revealed with the antibodies N675 (Fig.20a), HDA (Fig.20.b) and HDC (Fig.20.c). Fluorescent fusion proteins were also detected with the EGFP antibody, specific for the derivatives of the GFP fluorescent protein (Fig.20.d).

Endogenous and overexpressed htt expressions were also investigated in cell lines and HdhQ150 mouse models which revealed different truncation products with different antibodies (Fig.21.)

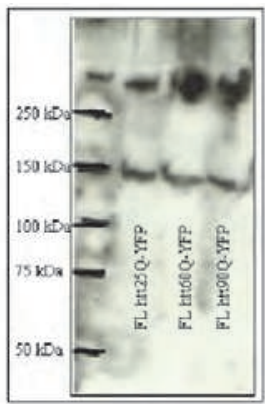

a

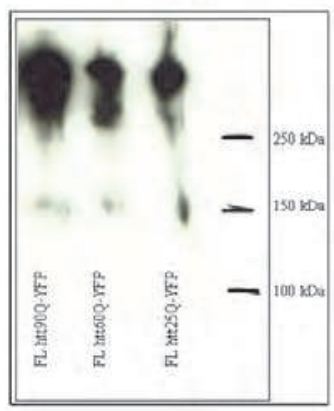

$\mathrm{c}$

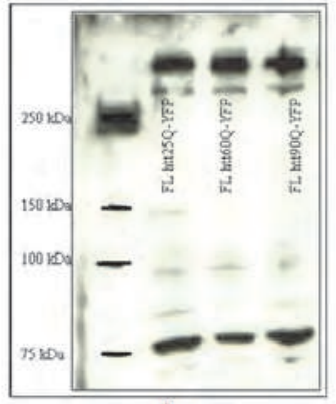

b

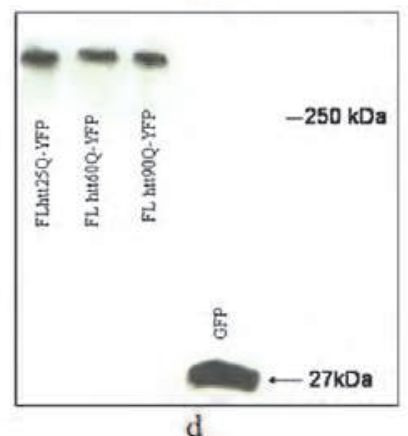

Fig. 20. Western blot of a 5\% SDS-PAGE gel with FL htt-YFP expression in HEK293 cells after N675 (a), HDA (b), HDC (c) and anti-GFP antibodies.
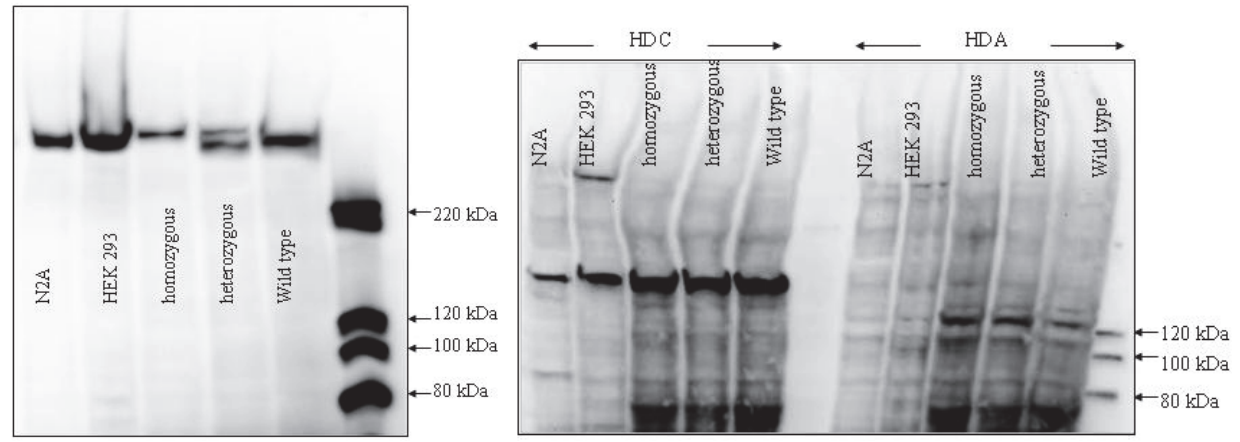

Fig. 21. Western blot of 3-8 \% SDS-PAGE gels, comparing htt expression in cell lines and HdhQ150 embryos using N675 (a), HDA and HDC antibodies (b). 


\section{Modeling htt in silico}

\subsection{Building 3D htt model via fold recognition}

The mechanisms leading to selective neurodegeneration can be explored via modeling the normal and mutant forms of the related proteins and analyzing their molecular structures. Most of the methods for protein structure prediction and modeling make use of the known structures of the homologous proteins. Htt shows no homology to any other counterparts, therefore it is not easy to identify its structure and assign its functions. However, since each protein folds into a unique 3D conformation, one should be able to predict its unknown structure using algorithms. Fold recognition method should be the method of choice when the protein of interest has no known homologues. Given a library of known structures, fold recognition determines which of them shares a folding pattern with the query protein, for which the sequence but not the structure is known (Lesk, A.M., 2008). A method for fold recognition is threading. The idea behind threading is to create many models for the query using many possible alignments between the known structures and the unknown protein. So, the threading method tries all possible folds and all possible alignments to establish the rough models. For successful fold recognition, the models should be scored and the best one should be selected. In addition to that, the scores should be calibrated to explore whether the rough model with the best score is likely to be correct.

There are programs available, like Jmol, Opendx, Rasmol, VMD and XCrySden, to determine the 3D structures of proteins. In this study VMD (Visual Molecular Dynamics) is used since the program is very user-friendly in constructing and analyzing the 3D molecular structures of the proteins. In addition to this, VMD shows $\alpha$-helix and $\beta$ - sheet structures, coils, turns and van der Waals bonds as well as protein sequence information, atomic arrangements and micromolecular details of the proteins (Gibas, C. \& Jambeck, P., 2002). VMD programme, provided by the University of Illinois at Urbana-Champaign, creates 3D structures of the proteins that are saved as PDB files (Humphrey et al., 1996). Since the program produces more reliable and fair results with short amino acid sequences, htt protein was loaded to the program as sequences of 400 amino acids (aa). For each 400 aa sequence, five best models were retrieved (Table 4.) Using HHpred programme, the best model for the polyQ-bearing first 400 aa sequence was identified to be the 1WA5_B model (Fig.22).

\begin{tabular}{|l|l|}
\hline Htt sequence & Best models \\
\hline $1^{\text {st }} 400 \mathrm{aa}$ & 1WA5_B, 1B3U_A, 1IBR_B, 1W9C_A, 1Q1S_C \\
\hline $2^{\text {nd }} 400$ aa & 1PAI_A, a.86.1.1.1, 1AO7_E, 1LP9_E, 1UP6_E \\
\hline $3^{\text {rd }} 400$ aa & 2GO2_A, 1X9D_A, 1EE5_A, 1Y2A_C ve 1Q1S_C \\
\hline $4^{\text {th }} 400$ aa & 1EE5_A, 1WA5_B, 2F6H_X, 2GO2_A, 2F5U_A \\
\hline $5^{\text {th }} 400$ aa & a.118.1.14.3_A, 1ZEE_A, 1GAI, 1Y2A_C,1Q1S_C \\
\hline $6^{\text {th }} 400$ aa & 2GFP_A, 1IBR_B, 1U7G_A, a.118.5.1.1_A, 1Y2A_C \\
\hline $7^{\text {th }} 400$ aa & 2F5U_A, 1RH5_A, 1IBR_B, 1YFM, 1C3C_A \\
\hline Last 344 aa & 1HZ4_A, a.118.4.1.1_A, 1XM9_A, 1N4M_A , 1Y2A_C \\
\hline
\end{tabular}

Table 4. Best models of htt. 


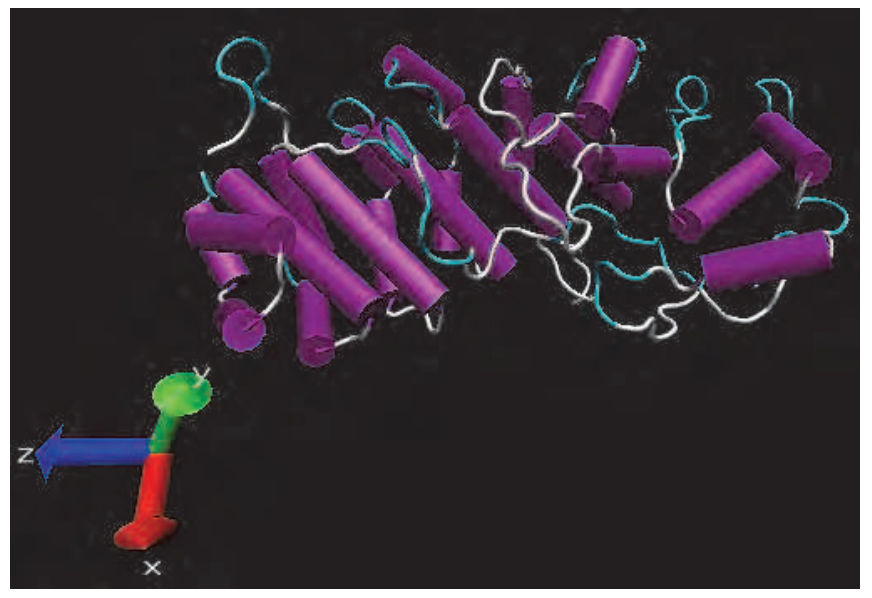

Fig. 22. The best model structure of the first 400 aa of htt.

The first 400 aa region of htt revealed parallel $\alpha$-helices and no $\beta$-sheets in the initial parts of the structure, the turns and coils were normal in length. In the second 400 aa part,the number of $\alpha$-helices decreased and $\beta$-sheets dominated, turn and coil structures were longer. The third 400 aa part showed long $\alpha$-helices and very few $\beta$-sheets. In addition to that, turn and coil structures were considerably longer and $\alpha$-helices tended to form tangles. the fourth 400 aa part resembles to the first part in terms of its $\alpha$-helix and $\beta$-sheet content, however turns and coils were longer. In the fifth 400 aa region, there were much less but longer $\alpha$-helices than that of the first part and they formed tangles. There were long coils and turns like that of the second part. Only one of the models have identified $\beta$-sheets in the fifth region. In the sixth 400 aa part of the protein, dense and parallel $\alpha$-helices were found to dominate. In some models $\alpha$-helices were considerably long. There were less number of $\alpha$-helices which were long and organized as tangles. Some models indicated $\beta$-sheets, turn and coil structures were longer than that of other protein regions. In the last part of the protein, the density of the $\alpha$-helices and the lengths of turns and coils were normal.

\subsection{Modeling htt mutation in silico}

In this part of the study, in silico polyQ expansion mutations were created by adding extra glutamine repeats to the first 400 aa part of the protein. Wild type normal htt protein is accepted to contain 23Qs. In humans, 27-35 CAGs show meiotic instability and 36-39 repeats are considered to show incomplete penetrance. Repeats above 40 definitely cause HD .In order to represent these stages, polyQ region of htt was made expanded with 10,13,14, 15, $16,20,25$ and 30 additional glutamines, which result in mutant proteins of 33, 36, 37, 38, 39, 43, 48 and 53Q. The mutant models were compared to the best model of the first 400 aa structure, 1WA5_B. According to the results, there is no significant structural change in the mutant proteins of 33, 36, 37 and 38Q. However, htt with 39 or more glutamines have shown conformational changes. Especially turn and coil regions were found to be longer and increased in number, and $\alpha$-helices were found to be shorter. One previous study has 
reported increased $\alpha$-helices and $\beta$-sheets, which was thought to be correlated with increased tendency to aggregate (Marchut, A.J.\& Hall, C.K., 2007). As a second step, models of only the polyQ regions of $36 \mathrm{Q}$ and $53 \mathrm{Q}$ proteins were constructed and compared to the polyQ region of the 1WA5_B model (Fig.23). It was noticed that the turn and coil structures were increased in number and $\alpha$-helices were shorter. In this situation, protein may gain non-covalent interactions within itself or with other proteins and aggregate in the form of twisted $\beta$-sheets.
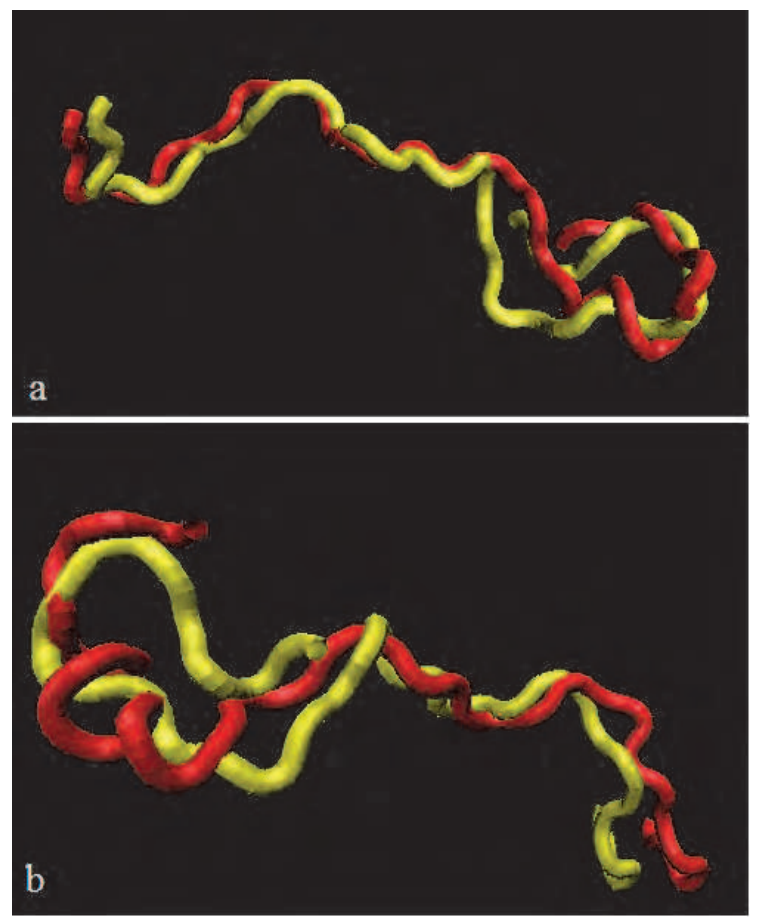

Fig. 23. Structural comparison of the polyQ regions of 1 WA5_B to that of mutant $36 \mathrm{Q}$ (a) and 53Q (b). Wild type polyQ region is indicated in yellow, mutant polyQs are in red color.

Conformational change due to CAG repeat expansion results in toxic gain of function in the mutant protein and leads to cellular toxicity. Toxic gain of function, in turn, results in loss of function of the normal htt (Cattaneo et al., 2001; Chen et al., 2003). This interplay starts inevitable neurodegeneration processes. Increase in the number of turns and coils, together with shortened $\alpha$-helices may result in folding of the protein within itself or favors its interactions with other polyQ proteins and its aggregation as $\beta$-pleated sheets. Research findings have identified aggregates in the form of $\beta$-sheets in vitro and in human HD brain (Scherzinger et al., 1997)., which can be explained by the previously proposed polar zipper model (Perutz et al., 1994). Distortion in the $\alpha$-helix structure and formation of $\beta$-sheets were also proved in other neurodegenerative disorders. It is apparent that $\beta$-sheets render the protein more susceptible to aggregate formation (Goedert, M., 1999; Murray et al., 2001). Lengthened turn and coil and shortened $\alpha$-helix structures significantly change the 
conformation of the protein. In this new conformation, conserved protein regions may become susceptible to cleavage by proteases which results in proteolysis, production of toxic htt fragments and regional pathology. On the other hand, conformational change may also cause deficiency in normal htt proteolysis, in that case toxicity comes into play due to inreased half life of the protein. It has been shown that aggregate-forming mutant htt is compatible with variable $\beta$-sheet/ $\beta$-turn model by using N-terminal htt in mammalian cell cultures and cortical neurons (Poirier et al., 2005). This proves that the resulting mutant structure is toxic to the cells. On the other hand, these intercellular aggregates can protect the cells against toxicity by isolating the mutant proteins in the cell (Rajagopalan, S. \& Andersen, J.K., 2001). Overall, expanded polyQ leads to a conformational change by favoring lengthened turns and coils and shortened $\alpha$-helices, which may lead to improper folding and aggregation of the mutant protein. Then, apoptosis follows when the cellular concentrations of the proteins are distorted.

\section{Conclusion}

Since the identification of the HD gene and its protein product, localization of both the endogenous and overexpressed htt has been investigated by several research groups in cell lines, animal models, and post-mortem patient tissues. However, after almost eighteen years, there is still no agreement on the precise distribution and function of htt. In the framework of this study, localization and expression patterns of endogenous and overexpressed htt were investigated in a variety of neuronal and non-neuronal cell lines (HEK 293, N2A, PC12, IMR32) and in embryonic striatal projection neurons expressing FL and truncated htt.

Endogenous htt was localized in cells using antibodies directed to $\mathrm{N}$ - and C-terminal regions of htt. The results demonstrated that htt is proteolysed as a cell type specific manner. Using the N-terminal antibody, localization of htt was found to be nuclear in neuronal cells, but cytoplasmic in the others. This suggests that hit might be processed differently in neuronal and non-neuronal cells. In the neurons, cleavage products might be small enough to enter into the nucleus by passive diffusion, or they might interact with proteins involved in nuclear functions and actively transported. In other words, htt cleavage and subsequent transportation to the nucleus might be required for the nuclear activities in neuronal cells. In addition, inclusions detected with the HDA antibody but not with N675, imply a different pool of N-terminal truncation products. In this study endogenous htt was shown to be exclusively cytoplasmic using the C-terminal antibody, with a diffuse and homogenous expression pattern. In neuronal cells localization was extended to the dendrites and concentrated in the nerve endings, suggesting a role in neurotransmission.

Overexpressed FL wild type and mutant htt with YFP tags were localized in the cytoplasm, regardless of the cell type. The possible effects of the $27 \mathrm{kDa}$ YFP on the localization of proteins were analyzed by using untagged htt constructs, however the localizations were shown to be the same. All cells examined expressed htt four hours after transfection, and have never entered into the nucleus in three days, after which they started to die. In addition, htt was shown to be localized to dendrites in neuronal cells, which again suggests 
a role in synaptic transmission. On the other hand, expression of full length mutant htt containing 60Q and 90Q was shown to be toxic to the cells, as verified with the cell viability assays. Cells transfected with the mutant constructs showed apoptotic features like membrane blebbing, large vacuoles and cellular dissociation. In addition, PC12 cells have failed to grow neurites when stimulated with NGF, which proves that mutant htt has a considerable effect on cellular growth. Proteolytic cleavage of overexpressed htt was shown on Western blots. Detection of overexpressed htt proteins in HEK 293 cells with N- and Cterminal antibodies has revealed a $150 \mathrm{kDa}$ htt fragment as well as the FL protein. Apparently, this large fragment cannot enter the nucleus by passive diffusion. On the other hand, differential processing of htt in different cell types is apparent on the gels. Overexpressed truncated wild type and mutant htt proteins show more nuclear, but also cytoplasmic localization. A few small nuclear inclusions were noticed with the wild type protein, but the mutant htt forms more and bigger inclusions, which increase in number and size in time.

Htt localization was also assessed in primary striatal neurons of HD mouse models expressing the FL and exon1 fragment of the protein. In both models, N-terminal antibodies recognized nuclear htt either diffuse or in the form of punctates, and the C-terminal antibody recognized htt exclusively in the cytoplasm. The localization and expression patterns were the same for striatal cells expressing wild type, heterozygous and homozygous mutant huntingtin. This implies that, in wild type and mutant embryonic striatal projection neurons, htt is cleaved and processed in similar ways.

Apart from evaluating htt localization in cell and animal models, 3D structures of normal and mutant htt were identified in order to correlate any conformational changes to disease pathology. The first 400 aa region of htt revealed parallel $\alpha$-helices and no $\beta$-sheets in the initial parts of the structure, the turns and coils were normal in length. In silico polyQ expansion mutations were resulted in increased number of turn and coil structures and shorter $\alpha$-helices in the polyQ region of htt. In this new conformation the protein may gain non-covalent interactions, fold improperly, resist degradation and aggregate in the form of $\beta$-sheets, which in turn depletes the soluble protein counterparts whose intracellular concentrations are crucial. In silico conformational changes due to expanded polyQ give clues about the pathogenic mechanisms of still unexplored neurodegeneration processes. Modeling mutant disease proteins in silico helps to predict possible changes in its conformation. Use of this information together with in vivo and in vitro protein localization data will help to explore the functions of the disease protein and the mechanisms involved in disease pathogenesis. In HD, where the molecular details of the neurodegeneration processes seem to be highly complex, concurrent evaluation of in vivo, in vitro and in silico data should better enlighten the way to discover selective neurodegeneration and ultimately to disease treatment.

\section{Acknowledgment}

The work presented here was supported by University of Wales College of Medicine (Cardiff, United Kingdom), Boğaziçi University (İstanbul, Turkey) and Haliç University (İstanbul, Turkey). 


\section{References}

Bae, B.I., Hara, M.R., Cascio M.B., Wellington, C.L., Hayden, M.R., Ross, C.A., Ha, H.C., Li, X.J., Snyder, S.H., Sawa, A. (2006). Mutant huntingtin: nuclear translocation and cytotoxicity mediated by GAPDH. Proc Natl Acad Sci USA, Vol.103, No.9, (Feb 2006), pp.3405-9, ISSN: 0027-8424

Cattaneo, E., Rigamonti,D., Goffredo, D., Zuccato, C., Squitieri, F. \& Sipione, S. (2001). Loss of normal huntingtin function: new developments in Huntington's disease research. Trends in Neurosciences, Vol.24, No.3, (March 2001), pp.182-188, ISSN: 0166-2236.

Chalfie, M. \& Kain, S. (eds). (1998). Green Fluorescent Protein Properties, Applications, and Protocols, Wiley-Liss, Inc., ISBN: 047117839X, 9780471178392, New York

Chen, Y.W., (2003). Local Protein Unfolding and Pathogenesis of Polyglutamine-Expansion Diseases. Proteins: Structure, Function, and Genetics, Vol.51, No.1, (April 2003), pp.6873, ISSN (printed): 0887-3585. ISSN (electronic): 1097-0134

Cooper, J. K., Schilling, G., Peters, M. F., Herring, W. J., Sharp, A. H., Kaminsky, Z., Masone, J., Khan, F. A., Delanoy, M., Borchelt, D. R., Dawson, V. L., Dawson, T. M.\& Ross, C. A. (1998). Truncated N-Terminal Fragments of Huntingtin with Expanded Glutamine Repeats form Nuclear and Cytoplasmic Aggregates in Cell Culture. Hum. Mol. Genet., Vol. 7, No. 5, (May 1998), pp.783-790, Online ISSN 1460-2083 Print ISSN 0964-6906

Davies, S., Turmaine, M., Cozens, B.A., DiFiglia, M., Sharp, A.H., Ross, C.A., Scherzinger, E., Wanker, E.E., Mangiarini, L. \& Bates, G.P. (1997). Formation of Neuronal Intranuclear Inclusions Underlies the Neurological Dysfunction in Mice Transgenic for the HD Mutation. Cell, Vol.90, No.3, (Aug1997), pp.537-548, ISSN 0092-8674

De Rooij, K. E., Dorsman, J. C., Smoor , M. A., Den Dunnen, J. T. \& Van Ommen, G. J. B. (1996). Subcellular Localization of the Huntington's Disease Gene Product in Cell Lines by Immunofluorescence and Biochemical Subcellular Fractionation. Hum. Mol. Genet., Vol. 5, No. 8, (Aug 1996), pp. 1093-1099, ISSN 0964-6906

DiFiglia, M., Sapp, E., Chase, K., Schwarz, C., Meloni, A., Young, C., Martin, E., Vonsattel, J. P., Carraway, R., Reeves, S. A., Boyce, F. M. \& Aronin, N. (1995). Huntingtin is a Cytoplasmic Protein Associated with Vesicles in Human and Rat Brain Neurons. Neuron, Vol. 14, No.5, (May 1995), pp.1075-1081, ISSN 0896-6273

DiFiglia, M., Sapp, E., Chase, K.O., Davies, S.W., Bates, G.P., Vonsattel, J.P. \& Aronin, N. (1997). Aggregation of Huntingtin in Neuronal Intranuclear Inclusions and Dystrophic Neurites in Brain. Science, Vol. 277, No.5334, (Sep 1997), pp. 1990-1993, ISSN: 0036-8075

Dragatsis, I., Levine, M. S. \& Zeitlin, S. (2000). Inactivation of Hdh in the Brain and Testis Results in Progressive Neurodegeneration and Sterility in Mice. Nat. Genet., Vol. 26, No. 3, (Nov 2000), pp. 300-306, ISSN: 1061-4036

Gibas,C.\& Jambeck,P. (2002). Einführung in die Praktische Bioinformatik. $1^{\text {st }}$ edition, O'Reilly Media, ISBN-10: 3897212897, ISBN-13: 978-3897212893, Köln 
Goedert, M. (1999). Filamentous nevre cell inclusions in neurodegenerative diseases: tauopathies and a- synucleinopathies. Philosophical Transactions of Royal Society London B, Vol.354, No.1386, (June 1999), pp.1101-1118, ISSN: 0080-4622

Graveland, G. A., Williams, R. S. \& DiFiglia, M. (1985). Evidence for degenerative and regenerative changes in neostriatal spiny neurons in Huntington's disease. Science, Vol. 227, No. 4688, (Feb 1985), pp. 770-773, ISSN: 0036-8075

Gutekunst, C. A., Levey, A. I., Heilman, C. J., Whaley, W. L., Yi, H., Nash, N. R., Rees, H. D., Madden, J. J. \& Hersch, S. M. (1995). Identification and Localisation of Huntingtin in Brain and Human Lymphoblastoid Cell Lines with Anti-Fusion Protein Antibodies. Proc. Natl. Acad. Sci. USA, Vol. 92, No. 19, (Sep 1995), pp.8710-8714, ISSN: 0027-8424

Hackam, A.S., Singaraja, R., Wellington, C. L., Metzler, M., McCutcheon, K., Zhang, T., Kalchman, M. \& Hayden, M. R. (1998). The influence of Huntington protein size on nuclear localisation and cellular toxicity. J. Cell Biol., Vol. 141, No. 5,(Jun 1998), pp. 1097-1105, ISSN: 0021-9525

Havel, L.S., Wang, C.E., Wade, B., Huang, B., Li, S. \& Li, X.J. (2011). Preferential accumulation of N-terminal mutant huntingtin in the nuclei of striatal neurons is regulated by phosphorylation. Hum Mol Genet., Vol.20, No.7, (1Apr 2011), pp.14241437, ISSN: 0964-6906

Hoogeveen, A.T., Willemsen, R., Meyer, N., de Rooij, K.E., Roos, R.A., van Ommen, G.J. \& Galjaard, H. (1993). Characterization and localization of the Huntington disease gene product. Hum Mol Genet., Vol.2, No.12, (Dec 1993), pp.2069-73, ISSN: 09646906

Housman D. (1995). Gain of Glutamines, Gain of Function? Nat. Genet., Vol. 10, No. 1, pp. 34, ISSN: 1061-4036

Humphrey, W., Dalke, A., Schulten, K. (1996). Visual Molecular Dynamics. J.Molec. Graphics, Vol.14, No.1, pp.33-38, ISSN 0263-7855

Huntington's Disease Collaborative Research Group. (1993). A Novel Gene Containing a Trinucleotide Repeat That is Expanded and Unstable on Huntington's Disease Chromosomes. Cell. Vol. 26, No. 72 (6), (Mar 1993), pp. 971-983, ISSN: 00928674

Jacobsen, J.C., Gregory, G.C., Woda, J.M., Thompson, M.N., Coser, K.R., Murthy, V., Kohane, I.S., Gusella, J.F., Seong, I.S., MacDonald, M.E., Shioda, T. \& Lee, J.M. (2011). HD CAG-correlated gene expression changes support a simple dominant gain of function. Hum Mol Genet., Vol.20, No.14, (15 Jul 2011), pp.2846-60. ISSN: 0964-6906

Jou, Y.S \& Myers, R.M. (1995). Evidence from antibody studies that the CAG repeat in the Huntington disease gene is expressed in the protein. Hum Mol Genet, Vol. 4, No. 3, (Mar 1995), pp.465-469, ISSN: 0964-6906

Juenemann, K., Weisse, C., Reichmann, D., Kaether, C., Calkhoven, C.F. \& Schilling, G. (2011). Modulation of mutant huntingtin N-terminal cleavage and its effect on aggregation and cell death. Neurotox Res., Vol.20, No.2, (Aug 2011), pp.120-133, ISSN: 0892-0362 
Kegel, K. B., Kim, M., Sapp, E., McIntyre, C., Castano, J. G., Aronin, N. \& DiFiglia, M. (2002). Huntingtin is Present in the Nucleus, Interacts with the Transcriptional Corepressor C-Terminal Binding Protein, and Represses Transcription. J. Biol. Chem., Vol. 277, No. 9, (Mar 2002), pp. 7466-7476. ISSN: 0021-9258

Landwehrmeyer, G. B., Mcneil, S. M., Dure, L. S., Ge P., Aizawa, H., Huang, Q., Ambrose, C. M., Duyao, M. P., Bird, E. D., Bonilla, E., De Young, M., Avila-Gonzales, A. J., Wexler, N. S., DiFiglia, M., Gusella, J. F., MacDonald, M. E., Penney, J. B., Young, A. B. \& Vonsattel, J. P. (1995). Huntington's Disease Gene: Regional and Cellular Expression in Brain of Normal and Affected Individuals. Ann. Neurol., Vol. 37, No. 2, pp. 218-230, ISSN: 0364-5134

Lesk, A.M. (2008). Introduction to Bioinformatics, Oxford University Press Inc. (3 ${ }^{\text {rd }}$ edition), ISBN 978-0-19-920804-3, New York .

Li, S. H., Schilling, G., Young, W. S. 3rd, Li, X.J., Margolis, R.L., Stine, O.C., Wagster, M.V., Abbott, M.H., Franz, M.L., Ranen, N.G., Folstein, S.E. , Hedreen, J.C.\& Ross, C.A. (1993). Huntington's disease gene (IT15) is widely expressed in human and rat tissues. Neuron, Vol.11, No.5, (Nov 1993), pp.985-93, ISSN: 0896-6273

Lin, C. H., Tallaksen-Greene, S., Chien, W.M., Cearley, J.A., Jackson, W.S., Crouse, A.B., Ren, S., Li, X.J., Albin, R.L., Detloff, P.J.(2001) Neurological abnormalities in a knock-in mouse model of Huntington's disease. Hum Mol Genet. Vol. 10, No.2, (March 2001), pp.137-44. , ISSN: 0964-6906

Mangiarini, L., Sathasivam, K., Seller, M., Cozens, B., Harper, A., Hetherington, C.,Lawton, M., Trottier, Y., Lehrach, H., Davies, S.W.\& Bates, G.P. (1996). Exon 1 of the HD gene with an expanded CAG repeat is sufficient to cause a progressive neurological phenotype in transgenic mice. Cell Vol.87 pp.493-506, ISSN 0092-8674

Marchut, A.J. \& Hall, C.K. (2007). Effects of Chain Length on the Aggregation of Model Polyglutamine Peptides: Molecular Dynamics Simulations. Proteins: Structure, Function, and Bioinformatics, Vol.66, No.1, (Jan 2007), pp.96-109, ISSN: 1097-0134

Martin-Aparicio, E., Avila, J. \& Lucas, J. L. (2002). Nuclear Localization of N-terminal Mutant Huntingtin is Cell Cycle Dependent. European Journal of Neuroscience, Vol. 16, No. 2, (Jul 2002), pp. 355-359, Online ISSN: 1460-9568

Murray, IVJ., Lee, VM.-Y. \& Trojanowski, JQ. (2001). Synucleinopathies: a pathological and molecular review. Clin Neurosci Res., Vol.1, No.6, (December 2001), pp.445-455, ISSN: 1566-2772.

Perutz, M. F., Johnson, T., Suzuki, M. \&. Finch, J. T. (1994). Glutamine Repeats as Polar Zippers: Their Possible Role in Inherited Neurodegenerative Diseases. Proc. Natl. Acad. Sci. USA, Vol. 91, pp. 5355-5358, ISSN: 0027-8424

Poirier, M.A., Jiang, H. \& Ross, C.H. (2005). A structure-based analysis of huntingtin mutant polyglutamine aggregation and toxicity: evidence for a compact beta-sheet structure, Hum. Mol. Genet., Vol.14, No.6, (15 March 2005), pp.765-77, ISSN: 09646906

Rajagopalan, S. \& Andersen, J.K. (2001). Alpha synuclein aggregation: Is it the toxic gain of funtion responsible for neurodegeneration in Parkinson's disease? Mechanisms of Ageing and Development, Vol.122, No.14, (30 Sep 2001), pp.1499-1510, ISSN: 00476374 
Scherzinger,E., Lurz,R., Turmaine,M., Mangiarini, L., Hollenbach, B., Hasenbank, R., Bates, G.P., Davies, S.W., Lehrach, H. \& Wanker, E.E. (1997). HuntigtinEncoded Polyglutamine Expansions Form Amyloid-like Protein Aggregates In Vitro and In Vivo. Cell, Vol.90, No.3, (August 1997), pp.549-558, ISSN: 00928674

Sharp, A. H., Loev, S. J., Schilling, G., Li, S. H., Li X. J., Bao, J., Wagster, M. V., Kotzuk, J. A., Steiner, J. P., Lo, A., Hedreen J. S. \& Ross, C. A. (1995). Widespread Expression of Huntington's Disease Gene (IT15) Protein Product. Neuron. Vol. 14, No.5, (May 1995), pp. 1065-1074, ISSN: 0896-6273

Strong, T. V., Tagle, D. A., Valdes, J. M., Elmer, L. W., Boehm, K., Swaroop, M., Kaatz, K. W., Collins, F. S. \& Albib, R. L. (1993). Widespread Expression of the Human and Rat Huntington's Disease Gene in Brain and Nonneural Tissues. Nature Genetics. Vol. 5, No. 3, (Nov 1993), pp. 259-265, ISSN: 1061-4036

Tanaka, Y., Igarashi, S., Nakamura, M., Gafni, J., Torcassi, C., Schilling, G., Crippen, D., Wood, J.D., Sawa, A., Jenkins, N.A., Copeland, N.G., Borchelt, D.R., Ross, C.A. \& Ellerby, L.M. (2006). Progressive Phenotype and Nuclear Accumulation of an Amino-Terminal Cleavage Fragment in a Transgenic Mouse Model with Inducible Expression of Full-length Mutant Huntingtin. Neurobiol. Dis., Vol. 21, No.2, (Feb 2006), pp. 381-391, ISSN: 0969-9961.

Trottier, Y., Devys, D., Imbert, G., Saudou, F., An, I., Lutz, Y., Weber, C., Agid, Y., Hirsch, E. C. \& Mandel, J. L. (1995). Cellular Localization of the Huntington's Disease Protein and Discrimination of the Normal and Mutated Form. Nature Genetics. Vol. 10, (May 1995), pp. 104-110, ISSN: 1061-4036

Wilkinson, F. L., Man, N. T., Manilal, S. B., Thomas, P., Neal, J. W., Harper, P. S., Jones, A. L. \& Morris, G. E. (1999). Localization of Rabbit Huntingtin Using a New Panel of Monoclonal Antibodies. Molecular Brain Research, Vol. 69, No. 1, (May 1999), pp. 10 20, ISSN: 0169-328X

Wyttenbach, A., Swartz, J., Kita, H., Thykjaer, T., Carmichael, J., Bradley, J., Brown, R., Maxwell, M., Schapira, A., Orntoft, T. F., Kato, K. \& Rubinsztein, D. C. (2001). Polyglutamine Expansions Cause Decreased Cre-Mediated Transcription and Early Gene Expression Changes Prior to Cell Death in an Inducible Cell Model of Huntington's Disease. Hum. Mol. Genet., Vol. 10, No. 17, (Jun 2001), pp. 1829-1845, ISSN: 0964-6906

Xia, J., Lee, D.H., Taylor, J., Vandelft, M. \& Truant, R. (2003). Huntingtin contains a highly conserved nuclear export signal. Hum. Mol. Genet., Vol.12, No.12, (Jun 2003), pp.1393-1403, ISSN: 0964-6906

Yan, Y., Peng, D., Tian, J., Chi, J., Tan, J., Yin, X., Pu, J., Xia, K. \& Zhang, B. (2011). Essential sequence of the $\mathrm{N}$-terminal cytoplasmic localization-related domain of Huntingtin and its effect on Huntingtin aggregates. Sci China Life Sci.,Vol.54, No.4, (Apr 2011), pp.342-350, ISSN: 1674-7305

Zeitlin, S., J. P. Liu, D. L. Chapman, V. E. Papaioannu \& Efstratiadis, A. (1995) Increased Apoptosis and Early Embryonic Lethality in Mice Nullizygous for the Huntington's Disease Gene Homologue. Nature Genetics, Vol. 11, pp. 155-163, ISSN: $1061-4036$ 
Zuccato, C., Ciammola, A., Rigamonti D., Leavitt, B. R., Goffredo, D., Conti, L., MacDonald, M. E., Friedlander, R. M., Silani, V., Hayden, M. R., Timmusk, T., Sipione, S. \& Cattaneo, E. (2001). Loss of Huntingtin-Mediated BDNF Gene Transcription in Huntington's Disease. Science, Vol. 293, No. 5529, (Jul 2001), pp. 493-498, ISSN: 0036-8075 


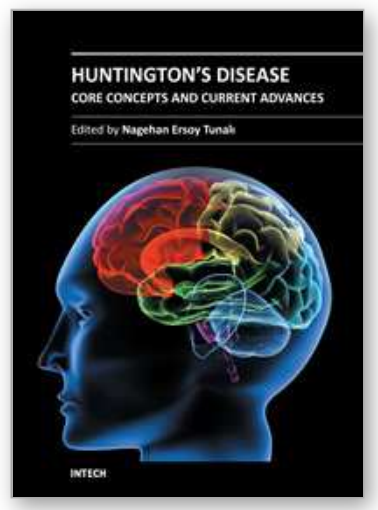

\author{
Huntington's Disease - Core Concepts and Current Advances \\ Edited by Dr Nagehan Ersoy Tunali
}

ISBN 978-953-307-953-0

Hard cover, 554 pages

Publisher InTech

Published online 15, February, 2012

Published in print edition February, 2012

Huntington's Disease is one of the well-studied neurodegenerative conditions, a quite devastating and currently incurable one. It is a brain disorder that causes certain types of neurons to become damaged, causing various parts of the brain to deteriorate and lose their function. This results in uncontrolled movements, loss of intellectual capabilities and behavioural disturbances. Since the identification of the causative mutation, there have been many significant developments in understanding the cellular and molecular perturbations. This book, "Huntington's Disease - Core Concepts and Current Advances", was prepared to serve as a source of up-to-date information on a wide range of issues involved in Huntington's Disease. It will help the clinicians, health care providers, researchers, graduate students and life science readers to increase their understanding of the clinical correlates, genetic aspects, neuropathological findings, cellular and molecular events and potential therapeutic interventions involved in HD. The book not only serves reviewed fundamental information on the disease but also presents original research in several disciplines, which collectively provide comprehensive description of the key issues in the area.

\title{
How to reference
}

In order to correctly reference this scholarly work, feel free to copy and paste the following:

Nagehan Ersoy Tunalı (2012). Modeling Huntington's Disease: in vivo, in vitro, in silico, Huntington's Disease Core Concepts and Current Advances, Dr Nagehan Ersoy Tunali (Ed.), ISBN: 978-953-307-953-0, InTech, Available from: http://www.intechopen.com/books/huntington-s-disease-core-concepts-and-currentadvances/modeling-huntington-s-disease-in-vivo-in-vitro-in-silico

\section{INTECH}

open science | open minds

\section{InTech Europe}

University Campus STeP Ri

Slavka Krautzeka 83/A

51000 Rijeka, Croatia

Phone: +385 (51) 770447

Fax: +385 (51) 686166

www.intechopen.com

\section{InTech China}

Unit 405, Office Block, Hotel Equatorial Shanghai

No.65, Yan An Road (West), Shanghai, 200040, China 中国上海市延安西路65号上海国际贵都大饭店办公楼 405 单元

Phone: +86-21-62489820

Fax: +86-21-62489821 
(C) 2012 The Author(s). Licensee IntechOpen. This is an open access article distributed under the terms of the Creative Commons Attribution 3.0 License, which permits unrestricted use, distribution, and reproduction in any medium, provided the original work is properly cited. 